\title{
Quantitative Evaluation of Radiation Damage to Polyethylene Terephthalate by Soft X-rays and High-energy Electrons
}

\author{
Jian Wang, Gianluigi A. Botton, Marcia M. West, and Adam P. Hitchcock* \\ Brockhouse Institute for Materials Research, McMaster University, Hamilton, ON, Canada L8S 4M1
}

Received: September 17, 2008; Revised Manuscript Received: December 12, 2008

\begin{abstract}
The chemical changes and absolute rates in radiation damage to polyethylene terephthalate (PET) caused by soft X-rays and energetic electrons have been measured using a scanning transmission X-ray microscope (STXM). Electron beam damage at two different dose rates and a range of doses was performed in an $80 \mathrm{keV}$ transmission electron microscope (TEM). The STXM beam was used to create damage patterns with systematically varied doses of monochromatic soft X-rays on an adjacent piece of the same PET sample. NEXAFS spectroscopy at the $\mathrm{C} 1 \mathrm{~s}$ and $\mathrm{O} 1 \mathrm{~s}$ edges was used to study the chemistry of the radiation damage and to determine quantitative critical doses for PET damage by both types of radiation. The spectral changes were similar for damage by electrons and X-rays, indicating the radiation chemistry is dominated by secondary processes, not the primary event. The critical dose for chemical changes determined from $\mathrm{C}$ 1s spectral features is $4.2(6) \times 10^{8} \mathrm{~Gy}$ and was the same for soft X-rays and electrons within measurement uncertainties. The critical dose for specific damage processes (as defined by changes in several different, bond-specific spectral features) was found to be similar in the $\mathrm{C} 1 \mathrm{~s}$ region and was comparable between $\mathrm{C} 1 \mathrm{~s}$ and $\mathrm{O}$ 1s edges for electron beam damage. There were statistically different critical doses for soft X-ray damage as probed by changes in $\mathrm{O} 1 \mathrm{~s}$ spectral features related to carbonyl and ester bonds.
\end{abstract}

\section{Introduction}

Radiation chemistry of polymers is important in a number of areas, including lithography technologies, ${ }^{1}$ polymer degradation, ${ }^{2}$ and processing of polymer materials to improve physical or chemical properties. ${ }^{3}$ Two major radiation sources used in these applications are X-rays and electron beams. Radiation damage of polymers induced by X-rays, particularly soft X-rays, is attracting growing attention. ${ }^{4-11}$ Better understanding of damage mechanisms and more accurate determinations of damage rates for polymers are not only important to the areas mentioned above, but also to the field of soft X-ray spectromicroscopy, which is increasingly being applied to organic materials ${ }^{12-15}$ and biological samples. ${ }^{14,16,17}$ A complete bibliography of soft X-ray spectromicroscopy has recently been published in association with a recent review of polymer applications $\mathrm{s}^{15}$ and updates can be obtained from http://unicorn. mcmaster.ca/xrm-biblio/xrm_bib.html. Relative to electron energy loss spectroscopy in transmission electron microscopes (TEMEELS), there is an advantage to using near edge $\mathrm{X}$-ray absorption spectroscopy (NEXAFS) in soft X-ray microscopes for inner shell excitation based analysis of radiation sensitive materials since the electron beam excites orders of magnitude more valence than inner shell ionizations, whereas monochromatic X-rays excite inner shell transitions essentially exclusively. That advantage was quantified in an early comparative study of damage to polyethylene terephalate (PET) by TEM-EELS versus nonspatially resolved NEXAFS. ${ }^{5}$ That study also reported a difference in critical doses for photon versus electron damage, which was noted at the time as unexpected but possibly associated with the very large difference in the dose density in the electron microscope versus the comparison between radiation damage of the same material in electron and X-ray microscope.

* Corresponding author: aph@mcmaster.ca; phone:(+1) 905 525-9140 x24749; fax: $(+1) 905$ 521-2773.
As the technology of both microscopies has improved immensely in the past decade, it is important to revisit the issue of relative damage rates, critical doses, and mechanisms for radiation damage to polymers.

Polyethylene terephthalate (PET, structure in Figure 1) is one of the most important commercial polymers with many excellent features, such as good radiation resistance with blockage of ultraviolet rays, high chemical resistance, low gas permeability, high heat resistance, and good transparency. ${ }^{18}$ Rates and critical doses for radiation damage of PET by different radiation sources and techniques have been reported. ${ }^{5,6,10}$ Rightor et al. ${ }^{5}$ compared the rate of damage to PET by soft X-rays, as measured by X-ray absorption spectroscopy (XAS), and by $100 \mathrm{keV}$ electron beams, as measured by TEM-based electron energy loss spectroscopy (TEM-EELS). In their study, the critical dose of PET was found to be $5 \sim 13$-fold larger for damage by soft X-rays than by 100 $\mathrm{keV}$ electrons. In addition, a $\sim 500$-fold advantage in terms of analytical information per unit damage was determined for XAS over TEM-EELS. However, within resolution limitations of the EELS system used in the experiments, the change in the near edge spectra was very similar in the two cases, indicating the damage products and mechanisms were most likely the same.

This paper reports an experimental study of the radiation damage of PET by X-ray and electron microscopes. Relative to the earlier study, ${ }^{5}$ the new aspects of these measurements include: (1) a scanning transmission X-ray microscope (STXM) with a focused spot size of $\sim 30 \mathrm{~nm}$ was used for the X-ray damage, resulting in a much higher dose density than the previous work using the 1996 version of the NSLS X-1A STXM in which a $500 \mathrm{~nm}$ beam size was used; (2) the analysis of the damage chemistry and quantitative changes was carried out by STXM for both X-ray and electron beam damage, which reduces possible inconsistencies associated with use of different analytical techniques and instruments for quantitative analysis. A brief preliminary report of this work has been published. ${ }^{10}$ It indicated 


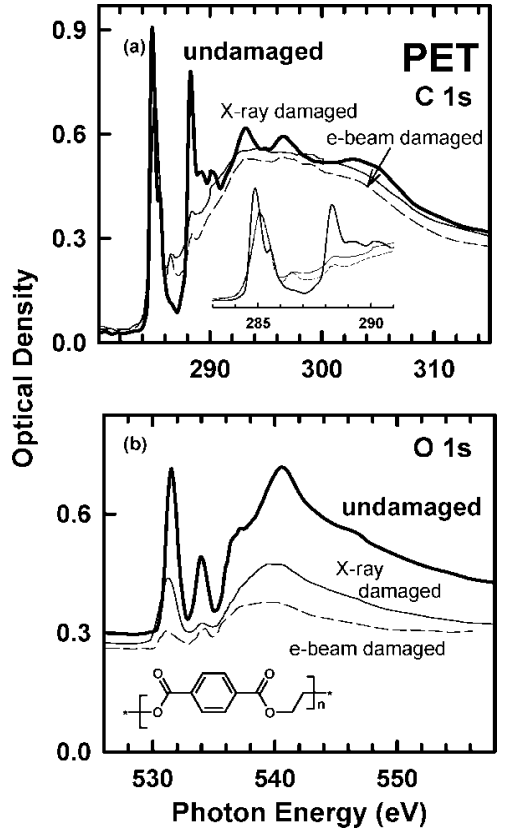

Figure 1. NEXAFS spectra of undamaged and soft X-ray and electron beam damaged PET. (a) $\mathrm{C} 1 \mathrm{~s}$ edge and (b) $\mathrm{O}$ 1s edge. In each plot the solid thick line is the undamaged spectrum, the thin solid line is the $\mathrm{X}$-ray spectrum from a region damaged at $3(\mathrm{C} 1 \mathrm{~s})$ or $2(\mathrm{O} 1 \mathrm{~s})$ times the critical dose, and the thin dashed line is the electron beam damaged spectrum from a region damaged at 2 times the critical dose. The insert shows an expanded region of the $\mathrm{C} 1 \mathrm{~s}$ spectra, illustrating there are significant changes in the shape of the $\mathrm{C} 1 \mathrm{~s} \rightarrow \pi^{*}$ peak around $285 \mathrm{eV}$ associated with $\mathrm{Ph}-\mathrm{COOR}$ bond breaking.

(contrary to ref 5) that the critical dose for chemical change (decrease to $1 / \mathrm{e}$ in intensity of specific spectral features) was the same for both X-ray and electron damage. Here we report a much more thorough, comparative study of X-ray and electron damage using an $80 \mathrm{keV}$ electron beam and selected monochromatic photon energies ( $300 \mathrm{eV} ; 528,531.6,534.1$ and 540.5 $\mathrm{eV})$. The chemical changes were monitored at selected energies in the $\mathrm{C} 1 \mathrm{~s}(284.8,286.5,288.2$, and $300 \mathrm{eV})$ and $\mathrm{O} 1 \mathrm{~s}(526$, $531.6,534.1$, and $560 \mathrm{eV}$ ) regions. Our main findings are: (1) critical doses are the same for X-ray and electron damage, within measurement uncertainties; (2) critical doses are the same for different bond breaking as tracked by changes at different spectral features (with a minor exception in the $\mathrm{O}$ 1s region); and (3) for the same absorbed dose, the mass loss induced by electron bombardment in vacuum is larger than that induced by X-ray absorption in He.

This paper is organized as follows. Section 2 presents sample preparation, experimental methods, and data treatment including evaluation of dose and derivation of the critical dose. Section 3.1 presents the NEXAFS spectroscopy of undamaged and damaged PET. This is followed by a quantitative determination of the critical dose in the $\mathrm{C} 1 \mathrm{~s}$ region by soft X-rays (Section 3.2.1) and electrons (Section 3.2.2); then the results for evaluation in the $\mathrm{O}$ 1s region are presented (Section 3.3). Radiation damage rates for the two techniques are compared and discussed in Section 4, followed by a brief summary in Section 5 .

\section{Experimental Section}

2.1. Sample Preparation. The sample of polyethylene terephthalate (PET) was obtained from the wall of a commercial soft drink bottle (known to be high purity, randomly oriented PET with a density of $1.35 \mathrm{~g} / \mathrm{cm}^{3}{ }^{18}$ ). It was used without further purification. No detectable contaminants were found by NEXAFS spectroscopy, and the C $1 \mathrm{~s}$ spectrum of the undamaged material is in very good agreement with earlier results. $5,13,19,20$ The PET thin films were prepared by ultra-microtoming a solid block to form $\sim 100 \mathrm{~nm}$ and $\sim 250 \mathrm{~nm}$ thick uniform films. The thinner films were used for $\mathrm{C} 1 \mathrm{~s}$ measurements, and the thicker films were used for $\mathrm{O} 1 \mathrm{~s}$ measurements. These film thicknesses were chosen to obtain appropriate optical density $(\mathrm{OD}=$ absorbance) at the $\mathrm{C} 1 \mathrm{~s}$ and $\mathrm{O} 1 \mathrm{~s}$ absorption edges.

2.2. STXM Damage. Radiation damage and spectral analysis of the damage products were carried out using the scanning transmission X-ray microscope (STXM) at beamline 5.3.2 at the Advanced Light Source. ${ }^{21}$ STXM uses a Fresnel zone plate to focus monochromated soft X-rays to a small probe $(\sim 30 \mathrm{~nm}$ in this work). The sample is raster-scanned with synchronized detection of transmitted X-rays to create images, and NEXAFS spectra are obtained using point scans, spectral line scans, or image sequence scans. The beamline, ${ }^{21}$ microscope ${ }^{22}$ and the methodology of quantitative radiation damage studies ${ }^{8,9,11,23}$ have been described elsewhere. The detector efficiency and absolute incident photon flux was determined with a calibrated silicon photodiode ${ }^{24}$ as presented in ref 11 and its Supporting Information. To study radiation damage by $\mathrm{X}$-rays, adjacent small areas of the sample (typically $0.6 \mu \mathrm{m} \times 0.6 \mu \mathrm{m}$, using $10 \times 10$ pixels) were exposed at a specific photon energy using systematically varied dwell times so as to span a range of doses that adequately sample the dose-damage curve. The exposures, carried out at five photon energies ( $300 \mathrm{eV}$; 528, 531.6, 534.1, and $540.5 \mathrm{eV}$ ), were performed automatically by a pattern generation routine ${ }^{8,9}$ in the STXM control and data acquisition software. A $\mathrm{N}_{2}$ gas filter was used to remove second order light for $\mathrm{C} 1 \mathrm{~s}$ measurements. After exposure, the damage patterns were imaged at specific photon energies-284.8, 286.5, 288.2, and $300 \mathrm{eV}$ in the $\mathrm{C} 1 \mathrm{~s}$ and 526, 531.6, 534.1, and $560 \mathrm{eV}$ in the $\mathrm{O} 1 \mathrm{~s}$ regions - selected to give the best contrast between damaged and undamaged regions as a result of chemical changes from the damage or to monitor mass loss. The transmission images were converted to OD images by normalization to the incident photon flux measured with the same detector (moving the beam to a position without sample). NEXAFS spectra of the undamaged and damaged regions were acquired using an image sequence ${ }^{25}$ with much lower photon flux.

The procedure for evaluating the radiation dose in STXM was presented elsewhere. ${ }^{8,9,11,23}$ The Beer-Lambert law was applied to calculate the absorbed radiation dose $a$ in units of MGy $\left(1 \mathrm{MGy}=10^{6} \mathrm{~J} / \mathrm{kg}=8.43 \mathrm{eV} / \mathrm{nm}^{3}\right.$ for PET $\left.{ }^{11}\right)$ according to:

$$
a(t)=\frac{I_{0}\left(1-e^{-\mathrm{OD}}\right) E t}{\varepsilon V \rho} \times 1.60 \times 10^{2}
$$

where $I_{0}$ is the incident flux (number of photons per second), $E$ is the exposure energy in $\mathrm{eV}, t$ is the exposure time in milliseconds (ms), $\varepsilon$ is the detector efficiency (measured to be $35(5) \%$ at the $\mathrm{C} 1$ s edge $^{11,22}$ and 50(5)\% at the $\mathrm{O} 1$ s edge $^{22}$ ), $V$ is the volume of the exposed region (considered to be the volume of a single pixel $=60 \mathrm{~nm} \times 60 \mathrm{~nm} \times l$, where $l$ is the thickness of the sample in nm, which is determined from the absorbance), $\rho$ is the sample density $\left(\mathrm{g} / \mathrm{cm}^{3}\right)$, and OD is the optical density of the exposed region during irradiation,. The latter is calculated dynamically, since there is some mass loss (especially for irradiation in the $\mathrm{O} 1 \mathrm{~s}$ region), thus the absorbance of the sample changes with increasing dose. For PET, the exposure energy 
was $300 \mathrm{eV}$ in the $\mathrm{C} \mathrm{1s} \mathrm{continuum,} \mathrm{and} \mathrm{there} \mathrm{was} \mathrm{negligible}$ carbon mass loss (for X-ray damage) so the OD was essentially constant during exposure. However, at the $\mathrm{O} 1 \mathrm{~s}$ edge, significant oxygen mass loss occurred during radiation damage. Thus, the dynamic OD values at exposure energies of 531.6, 534.1, and $540.5 \mathrm{eV}$ were used for accurate dose evaluation. ${ }^{23}$

For quantitative characterization of the radiation damage kinetics, the dose versus remaining OD at each analysis energy was fit to postulated first-order kinetics: ${ }^{4-11}$

$$
\mathrm{OD}(t)=\mathrm{OD}(\infty)+C \exp \left(-\frac{a(t)}{a_{\mathrm{c}}}\right)
$$

where $\mathrm{OD}(t)$ is the remaining optical density of the exposed region at the analysis energy, $\mathrm{OD}(\infty)$ is the extrapolated optical density after infinite dose, $C$ is a constant, equal to the damage at infinite $\operatorname{dose}\left(D_{\infty}=\mathrm{OD}(0)-\mathrm{OD}(\infty)\right.$, where $\mathrm{OD}(0)$ is the initial optical density) in ideal case, and $a_{\mathrm{c}}$ is the critical dose, that is, the dose required to attenuate (or increase, in the case of feature growth upon radiation damage) the OD at the analysis energy by $(1-1 / \mathrm{e})$ or $63 \%$ of the infinite damage $\left(D_{\infty}\right)$. To compare different layer thickness and polymer materials, both sides of eq 2 are divided by the initial optical density, $\mathrm{OD}(0)$, (or divided by the infinite optical density, $\mathrm{OD}(\infty)$, in the case of feature growth) at the corresponding analysis energy to get the normalized optical density as a function of radiation dose. The critical dose was obtained from the least-squares optimized slope of a plot of $\ln (\mathrm{OD}(t)-\mathrm{OD}(\infty))($ or $\ln (\mathrm{OD}(\infty)-\mathrm{OD}(t))$ in the case of feature growth) versus the dose, $a(t)$.

2.3. TEM Damage. Radiation damage to a 95(4) $\mathrm{nm}$ PET thin film was generated using the $80 \mathrm{keV}$ electron beam of a JEOL-1200EX transmission electron microscope at McMaster. Although $80 \mathrm{keV}$ is a lower energy than used in many modern analytical transmission electron microscopes, this instrument and beam energy were chosen so that the knock-on damage ${ }^{26,27}$ is limited, thus allowing a suitable comparison of damage by energy transfer, which more closely corresponds to that created by X-ray absorption, rather than momentum transfer. Two series of round spots were created on the PET film by the $80 \mathrm{keV}$ electron beam. Series A spots were made by a $1.3 \mu \mathrm{m}$ diameter electron beam and $40 \mathrm{pA}$ beam current with 1-20 s exposure times; series B spots were made by a $2.6 \mu \mathrm{m}$ diameter electron beam and $880 \mathrm{pA}$ beam current with 1-30 s exposure times. After damage in the TEM, the sample was removed, transported to Berkeley, and analyzed by STXM. Images were recorded at selected photon energies to track the chemistry changes and mass loss, and they were further converted to optical density images. Finally, NEXAFS spectra of the undamaged and electron and X-ray damaged regions were acquired using image sequences of the damaged areas.

The dose evaluation in TEM used the same principles as used in the previous work ${ }^{5}$ and was based on modeling the inelastic collision processes of high energy electrons. The radiation dose $a$ (in units of Gy) was calculated as:

$$
a=\frac{i_{0} \Delta E\left(\frac{l}{\mathrm{IMFP}}\right) t}{V \rho} \times 10^{-9}
$$

where $i_{0}$ is the incident electron beam current (pA); $\Delta E$ is the mean energy loss per inelastic scattering event by an $80 \mathrm{keV}$ electron $(\Delta E=80 \mathrm{eV}$, estimated from values reported for organic materials and water $\left.{ }^{28}\right) ; l$ is the thickness of the sample
TABLE 1: The Major $C$ 1s and $O$ 1s NEXAFS Features of Undamaged and Soft X-ray or Electron Beam Damaged

\begin{tabular}{|c|c|c|}
\hline \multicolumn{2}{|c|}{ energy $(\mathrm{eV})( \pm 0.1 \mathrm{eV})$} & \multirow[b]{2}{*}{ assignment } \\
\hline undamaged & damaged & \\
\hline \multicolumn{3}{|c|}{$\mathrm{C} 1 \mathrm{~s}$} \\
\hline 284.8 & \multirow[t]{2}{*}{285.1} & $\pi_{\mathrm{C}}^{*}=\mathrm{C}-\mathrm{H}$ \\
\hline 285.4 & & $\pi_{\mathrm{C}=\mathrm{C}-\mathrm{C}}^{*}$ \\
\hline & \multirow[t]{7}{*}{286.5} & $\pi_{\mathrm{C}=\mathrm{O}}^{*}($ aldehyde $)$ \\
\hline 288.2 & & $\pi_{\mathrm{O}=\mathrm{C}-\mathrm{OR}}^{*}$ (ester) \\
\hline 289.1 & & $\pi_{\mathrm{C}=\mathrm{C} / \mathrm{C}=\mathrm{O}}^{*}$ (ester) \\
\hline 290.2 & & $\pi_{\mathrm{C}}^{*}=\mathrm{C} / \mathrm{C}=\mathrm{O}$ (ester) \\
\hline 293.1 & & $\sigma_{\mathrm{C}-\mathrm{C}}^{*}$ \\
\hline 296.4 & & $\sigma_{\mathrm{C}-\mathrm{C}}^{*}$ \\
\hline 303.5 & & $\sigma_{\mathrm{C}=\mathrm{O}}^{*}$ \\
\hline \multicolumn{3}{|c|}{$\mathrm{O} 1 \mathrm{~s}$} \\
\hline & 531.2 & $\pi_{\mathrm{C}=\mathrm{O}}^{*}$ (aldehyde $)$ \\
\hline 531.6 & & $\pi_{\mathrm{O}=\mathrm{C}-\mathrm{OR}}^{*}($ ester $)$ \\
\hline 534.1 & & $\left(\mathrm{O}-\mathrm{CH}_{2}\right) \rightarrow \pi_{\mathrm{C}}^{*}=\mathrm{O}$ \\
\hline 537.1 & & O 1 s continuum onset \\
\hline 540.5 & 539.7 & $\sigma_{\mathrm{C}-\mathrm{O}}^{*}$ \\
\hline 546.5 & & $\sigma_{\mathrm{C}}^{*}=\mathrm{O}$ \\
\hline
\end{tabular}

PET

in $\mathrm{nm}$; IMFP is the electron inelastic mean free path (IMFP = $100 \mathrm{~nm}$ for a $80 \mathrm{keV}$ electron in PET, estimated from values reported for organic materials and water ${ }^{28}$ ); $t$ is the exposure time in seconds (s); $V$ is the volume of the exposed region in $\left(\mathrm{cm}^{3}\right)$; and $\rho$ is the polymer density $\left(\mathrm{g} / \mathrm{cm}^{3}\right)$. The derivation of the critical dose from dose-damage data for TEM damage followed the same procedure as used for STXM.

\section{Results}

3.1. NEXAFS Spectra of Undamaged and Radiation Damaged PET. Soft X-ray damage to PET at the C 1s edge was made by patterned exposure at $300 \mathrm{eV}$ for a series of exposure times. The $\mathrm{C} 1 \mathrm{~s}$ NEXAFS spectra of undamaged and heavily damaged PET are shown in Figure 1a. The insert to Figure 1a shows an expanded view of the discrete spectral region. The peak positions and assignments of the NEXAFS spectrum of undamaged PET are listed in Table 1. The major spectral features are: $\mathrm{C} 1 \mathrm{~s}(\mathrm{C}-\mathrm{H}) \rightarrow \pi_{\mathrm{C}=\mathrm{C}}^{*}$ transitions at 284.8 $\mathrm{eV}$ (phenyl ring $\mathrm{C}-\mathrm{H}$ ) and $\mathrm{C} 1 \mathrm{~s}(\mathrm{C}-\mathrm{R}) \rightarrow \pi_{\mathrm{C}=\mathrm{C}}^{*}$ transitions at $285.4 \mathrm{eV}$ (phenyl ring $\mathrm{C}-\mathrm{COOR}$ ); the $\mathrm{C} 1 \mathrm{~s}(\mathrm{C}=\mathrm{O}) \rightarrow \pi_{\mathrm{O}}^{*}=\mathrm{C}-\mathrm{OR}$ transitions of the ester group at $288.2 \mathrm{eV}$; the mixed $\pi_{\mathrm{C}=\mathrm{C} / \mathrm{C}=\mathrm{O}}^{*}$ at 289.1 and $290.2 \mathrm{eV}$; and $\sigma^{*}$ features at 293.1, 296.4, and $303.5 \mathrm{eV}$. Similar spectroscopic energies and assignments were reported earlier. ${ }^{5}$ The X-ray (or electron) damaged PET is characterized by a number of spectroscopic changes (Figure 1a and Table 1). First, there is a decrease, loss, and merging of $\mathrm{C}-\mathrm{R}$ fine structure features at 284.8 and $285.4 \mathrm{eV}$ associated with the phenyl ring, mainly caused by bond cleavage between the ester group and the phenyl ring, as has been documented by the core excitation spectra and calculations of gaseous terephthaldehyde, benzoic acid ethyl ester, and benzaldehyde. ${ }^{29}$ Second, there is a decrease of the $\mathrm{C} 1 \mathrm{~s}(\mathrm{C}=\mathrm{O}) \rightarrow \pi_{\mathrm{O}=\mathrm{C}-\mathrm{OR}}^{*}$ transition at $288.2 \mathrm{eV}$ and creation of a $\mathrm{C} 1 \mathrm{~s}(\mathrm{C}=\mathrm{O}) \rightarrow \pi_{\mathrm{C}=\mathrm{O}}^{*}$ feature at $286.5 \mathrm{eV}$ due to $\mathrm{C}-\mathrm{O}$ bond dissociation in the ester groups that generates benzaldehyde moieties. Third, there is a decrease and restructuring of the delocalized $\mathrm{C} 1 \mathrm{~s}(\mathrm{C}=\mathrm{O}) \rightarrow$ $\pi_{\mathrm{C}=\mathrm{O}}^{*}$ features between 289 and $290 \mathrm{eV}$. Fourth, the broad continuum structures between 292 and $308 \mathrm{eV}$ are washed out due to a wider range of $\mathrm{C}-\mathrm{C}$ and $\mathrm{C}-\mathrm{O}$ bond types in the damaged material. Although there is likely some mass loss, the amount of carbon lost is very small since the C 1s pre-edge and the intensity of the $\mathrm{C} 1 \mathrm{~s}$ continuum above $310 \mathrm{eV}$ are 
maintained at almost the same level even in the most damaged PET. The intensity in the $\mathrm{C} 1 \mathrm{~s}$ continuum is proportional to the total carbon mass of the material. ${ }^{6}$ We note that there is a slow build-up of carbon on samples in STXM5.3.2 ${ }^{11}$ for multisecond exposures, and it is possible that carbon build-up balances some carbon loss. It is estimated that about $5 \mathrm{~nm}$ of amorphous/ graphitic carbon was photodeposited under the exposure conditions, which is small relative to the measured film thickness of 95(4) $\mathrm{nm}$.

The spectrum of electron beam damaged PET (Figure 1a) was similar to that for X-ray damaged PET except that the preedge and the $\mathrm{C} 1 \mathrm{~s}$ continuum were lower than those of the undamaged material by $\sim 13 \%$ when the dose $\left(7.7 \times 10^{2} \mathrm{MGy}\right)$ was such that the signal at $288.2 \mathrm{eV}$ ester groups just disappeared, as shown in Figure 1a. Higher doses using the 200 $\mathrm{keV}$ beam of a JEOL2010F microscope resulted in extremely large mass loss in TEM, eventually resulting in perforation of the film (results not shown).

Soft X-ray damage to PET at O 1s energies was made by irradiation at $531.6 \mathrm{eV}$ (the $\mathrm{O} 1 \mathrm{~s} \rightarrow \pi_{\mathrm{C}=\mathrm{O}}^{*}$ transition) for a series of exposure times. For this study a thicker PET sample was used $(250(8) \mathrm{nm})$ in order to increase the absorbance. The $\mathrm{O} 1 \mathrm{~s}$ NEXAFS spectra of undamaged and heavily damaged PET are shown in Figure 1b. The NEXAFS feature positions and assignments are summarized in Table 1 . The $O$ 1s NEXAFS spectrum of PET undergoes several spectroscopic changes with radiation damage. First, there is a large decrease of the two strong resonant features at $531.6 \mathrm{eV}\left(\mathrm{O} 1 \mathrm{~s} \rightarrow \pi_{\mathrm{O}}^{*}=\mathrm{C}-\mathrm{OR}\right)$ and at $\left.534.1 \mathrm{eV} \mathrm{O} 1 \mathrm{~s}\left(\mathrm{CH}_{2}-\mathrm{O}\right) \rightarrow \pi_{\mathrm{C}=\mathrm{O}}^{*}\right)$. Second, there is a large decrease of the $\sigma^{*}$ features at 540.5 and $546.5 \mathrm{eV}$, the $\mathrm{O} 1 \mathrm{~s}$ continuum onset at $537.1 \mathrm{eV}$ and throughout the $\mathrm{O} 1 \mathrm{~s}$ continuum; and (3) there is a small decrease of the pre-edge intensity. The decrease of the $531.6 \mathrm{eV}$ peak is due to destruction of carbonyl functional groups, whereas the decrease of the 534.1 $\mathrm{eV}$ peak is due to cleavage of the $\mathrm{C}-\mathrm{O}$ bond in the ester group. When all the ester groups were cleaved and damaged, as suggested by the disappearance of the $534.1 \mathrm{eV}$ feature, the $\pi_{\mathrm{C}=\mathrm{O}}^{*}$ feature at $531.6 \mathrm{eV}$ and the $\sigma_{\mathrm{C}-\mathrm{O}}^{*}$ feature at $540.5 \mathrm{eV}$ are shifted down to 531.2 and $539.7 \mathrm{eV}$, respectively. This is consistent with formation of isolated carbonyl groups such as aldehydes (or ketones) ${ }^{20}$ in the damaged polymer, as is also suggested by the $\mathrm{C} 1 \mathrm{~s}$ spectral changes. There is considerable loss of oxygen, as shown by a large intensity decrease ( $\sim 50 \%)$ in the $\mathrm{O} 1 \mathrm{~s}$ continuum (Figure 1b). This is consistent with loss of species with high percentages of oxygen, such as $\mathrm{O}_{2}, \mathrm{CO}_{2}$, and $\mathrm{CO}$.

The O 1s spectrum of electron beam damaged PET was also measured for the same damage spot as for $\mathrm{C} 1 \mathrm{~s}$ (Figure 1b). It is slightly different to the $\mathrm{O} 1 \mathrm{~s}$ spectrum of X-ray damaged PET; in particular, there is a larger decrease in the $531.6 \mathrm{eV}$ feature and much greater oxygen mass loss.

3.2. Quantitative Evaluation of PET Damage in the $\mathrm{C}$ 1s Edge: STXM versus TEM. 3.2.1. STXM Damage. Figure 2 illustrates the quantitative determination of critical dose for soft $\mathrm{X}$-ray damage of PET by $300 \mathrm{eV}$ photons, with the damage monitored at 284.8, 286.5, and $288.2 \mathrm{eV}$. Figure 2a includes optical density images at 284.8, 286.5, 288.2, and $300 \mathrm{eV}$ of a uniform region of a PET film that was damaged in a pattern of nine pads where each pad was subjected to a dwell time per pixel varying between 75 and $3000 \mathrm{~ms}$, at a photon energy of $300 \mathrm{eV}$ and a dose rate of 7.8(4) $\times 10^{2} \mathrm{MGy} / \mathrm{s}$. The 9-pad pattern is clearly visualized at $284.8,286.5$, and $288.2 \mathrm{eV}$, representing $\mathrm{OD}$ changes in the damaged regions due to chemistry changes. In contrast, the pattern was barely visible (a)
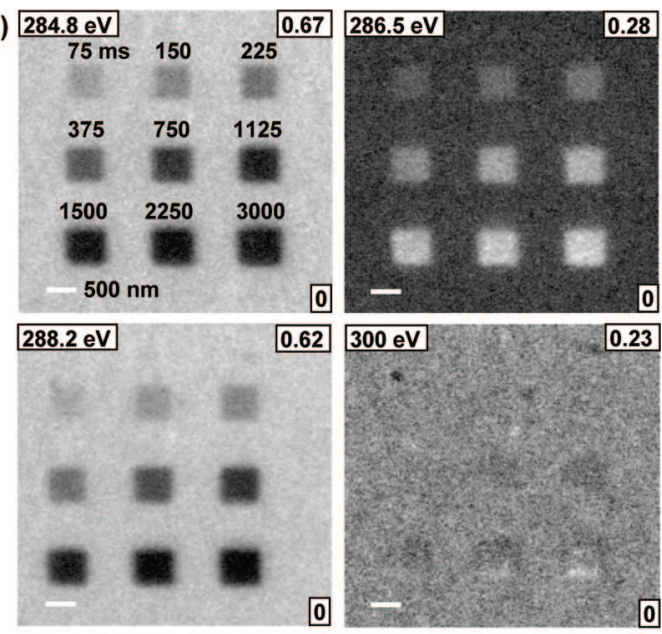

(b)

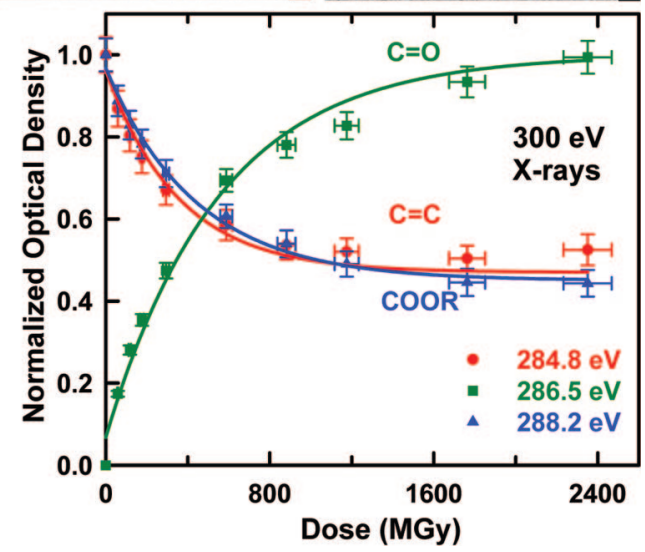

Figure 2. C 1s STXM analysis of X-ray beam damage of PET. (a) Patterns created in an initially undamaged, free-standing uniform 95(4) $\mathrm{nm}$ thin film by exposure at $300 \mathrm{eV}$ using a $10 \times 10$ pixel, $0.6 \mu \mathrm{m} \times$ $0.6 \mu \mathrm{m}$ raster scan with the indicated per-pixel dwell times (ms) and a dose rate of 7.8(4) $\times 10^{2} \mathrm{MGy} / \mathrm{s}$, then imaged at 284.8, 286.5, 288.2, and $300 \mathrm{eV}$. The numbers in the lower and upper right boxes on each image are the gray scale limits of the optical density. (b) Plots of the normalized optical density at $284.8,286.5$, and $288.2 \mathrm{eV}$ as a function of radiation dose for PET damaged by exposure to $300 \mathrm{eV}$ X-rays.

at $300 \mathrm{eV}$, consistent with negligible carbon mass loss and thus little change in $\mathrm{C} 1 \mathrm{~s}$ continuum absorption. Note there are bright lines at the lower boundary of the most heavily damaged pads in the OD image recorded at $300 \mathrm{eV}$. These most likely correspond to carbon build-up in the first line of the pad, which is overexposed relative to the rest of the pad due to a flaw in the control software. This region was not included in the evaluation of the quantitative dose-damage. Figure $2 \mathrm{~b}$ plots the normalized OD at 284.8, 286.5, and $288.2 \mathrm{eV}$ as a function of radiation dose for PET after exposure at $300 \mathrm{eV}$. The damage of the ester group was monitored at $288.2 \mathrm{eV}$, and the development and growth of the carbonyl group generated due to $\mathrm{C}-\mathrm{O}$ bond dissociation in the ester groups was tracked at $286.5 \mathrm{eV}$. The cleavage between the ester group and the phenyl ring results in a decrease in the optical density at 284.8 and $285.4 \mathrm{eV}$ (data not shown due to the small size of this shoulder, which makes it difficult to accurately define the change). Damage of the phenyl ring could be tracked by following changes at $285.0 \mathrm{eV}$ in the damaged PET (see Figure 1a inset for details). However, damage to phenyl rings requires a much higher radiation dose, ${ }^{11,23}$ such that negligible change was detected in the dose regime explored in this study. For each of the curves shown in Figure $2 b$, the radiation dose versus normalized OD was fit to eq 2 using extrapolated normalized $\mathrm{OD}_{\infty}$ values of $0.45(5)$ at $288.2 \mathrm{eV}, 1.00(5)$ at $286.5 \mathrm{eV}$, and 
TABLE 2: Photon Energies, Normalized Infinite Optical Densities, and Derived Critical Doses from C 1s Analysis of PET Damaged by $300 \mathrm{eV}$ X-rays or an $80 \mathrm{keV}$ Electron Beam

\begin{tabular}{|c|c|c|c|c|c|c|}
\hline & & \multirow[b]{2}{*}{$\begin{array}{l}\text { STXM }^{a} \\
\text { damage }\end{array}$} & \multirow[b]{2}{*}{$\begin{array}{c}\text { TEM }^{b} \\
\text { damage A }\end{array}$} & \multirow[b]{2}{*}{$\begin{array}{c}\text { TEM }^{b} \\
\text { damage B }\end{array}$} & \multicolumn{2}{|c|}{ literature } \\
\hline \multicolumn{2}{|c|}{ damage process } & & & & $\begin{array}{c}\text { X-ray } \\
\text { damage }\end{array}$ & $\begin{array}{c}\text { electron } \\
\text { beam damage }\end{array}$ \\
\hline \multirow{2}{*}{$\mathrm{Ph}$-COOR cleavage } & $\mathrm{OD}_{\infty}{ }^{c}$ & $0.45(5)$ & $0.40(5)$ & $0.40(5)$ & & \\
\hline & critical dose $\left(\times 10^{2}\right.$ MGy $)$ & 3.9(6) & 3.8(5) & 3.4(5) & $20(2)^{d}$ & $1.5(1)^{d}$ \\
\hline \multirow[t]{2}{*}{$\mathrm{C}=\mathrm{O}$ growth } & energy $(\mathrm{eV})$ & 286.5 & 286.5 & 286.5 & 286.7 & \\
\hline & $\mathrm{OD}_{\infty}{ }^{c}$ & $1.00(5)$ & $1.00(5)$ & $1.00(5)$ & & \\
\hline \multirow{2}{*}{ COOR damage } & $\mathrm{OD}_{\infty}^{c}$ & $0.45(5)$ & $0.40(5)$ & $0.40(5)$ & & \\
\hline & critical dose $\left(\times 10^{2}\right.$ MGy $)$ & $4.2(6)$ & $4.2(6)$ & $3.8(5)$ & $8.9(9)^{d}, 25(1)^{e}$ & $1.9(1)^{d}$ \\
\hline \multirow[t]{2}{*}{ carbon mass loss } & energy $(\mathrm{eV})$ & 300 & 300 & 300 & $315^{e}$ & \\
\hline & $\mathrm{OD}_{\infty}{ }^{c}$ & $1.00(5)$ & $0.87(5)$ & $0.87(5)$ & $0^{e}$ & \\
\hline
\end{tabular}

\begin{abstract}
${ }^{a}$ Dose rate for the X-ray damage was $7.8(4) \times 10^{2} \mathrm{MGy} / \mathrm{s}$, corresponding to a dose density of $66(3) \times 10^{2} \mathrm{eV} /(\mathrm{nm})^{3},(1 \mathrm{MGy}=8.43 \mathrm{eV} /$ $\mathrm{nm}^{3}$ for $\left.\mathrm{PET}^{11}\right) .{ }^{b}$ The beam current (pA) measured on the view screen of the JEOL1200 TEM is 10 times smaller than the current passing through the sample (B. Legge, JEOL, private communication). For the damage (A) series the spot diameter was $1.3 \mu \mathrm{m}$, and the beam current measured at the view screen was $4 \mathrm{pA}$. After current correction the dose rate was $0.18(3) \times 10^{2} \mathrm{MGy} / \mathrm{s}$, corresponding to a dose density of $1.5(3) \times 10^{2} \mathrm{eV} /(\mathrm{nm})^{3}$. For the damage (B) series the spot diameter was $2.6 \mu \mathrm{m}$, and the beam current measured at the view screen was $88 \mathrm{pA}$. After current correction the dose rate was $1.3(2) \times 10^{2} \mathrm{MGy} / \mathrm{s}$, corresponding to a dose density of $11(2) \times 10^{2} \mathrm{eV} /(\mathrm{nm})^{3}$. ${ }^{c} \mathrm{OD} \infty$ is the normalized optical density after infinite dose. ${ }^{d}$ Reference $5 .{ }^{e}$ Reference 6.
\end{abstract}

$0.45(5)$ at $284.8 \mathrm{eV}$. The derived critical doses were: $4.2(6) \times$ $10^{2} \mathrm{MGy}$ at $288.2 \mathrm{eV}$, corresponding to ester group damage; $4.8(7) \times 10^{2} \mathrm{MGy}$ at $286.5 \mathrm{eV}$, corresponding to carbonyl group growth; and 3.9(6) $\times 10^{2} \mathrm{MGy}$ at $284.8 \mathrm{eV}$, corresponding to cleavage between the ester group and the phenyl ring. The results are summarized in Table 2 and are compared to literature values of the critical dose for damage to PET ${ }^{5,6}$

3.2.2. TEM Damage. Figure 3 presents the quantitative evaluation of damage to PET by $80 \mathrm{keV}$ electrons, analyzed by STXM images recorded at 284.8, 286.5, 288.2, and $300 \mathrm{eV}$. Figure 3 a displays optical density images at these energies of a uniform region of a PET film that was damaged by two series of electron beam spots with the indicated exposure conditions. The calculated dose rate for the electron beam damage was $0.18(3) \times 10^{2}$ and $1.3(2) \times 10^{2} \mathrm{MGy} / \mathrm{s}$ for series $\mathrm{A}$ and $\mathrm{B}$, respectively. The damage spots were clearly seen at 284.8 , 286.5 , and $288.2 \mathrm{eV}$, indicating OD changes in the damaged spots associated with chemistry changes. The damage spots were not visible at $300 \mathrm{eV}$ for series $\mathrm{A}$ due to the lower dose and thus negligible carbon mass loss. However, the series B damage spots were evident at $300 \mathrm{eV}$ because the higher dose rate and integrated dose resulted in some knock-on damage, ${ }^{26,27}$ which is the origin of the rim associated with carbon build-up around each of the series B spots. Figure $3 \mathrm{~b}$ plots the normalized optical density at 284.8, 286.5, and $288.2 \mathrm{eV}$ as a function of radiation dose for the two series of TEM damage. Series A has a better sampling of the dose-damage relationship than series B, for which the spectral damage is saturated after only 3 data points. Only the first four data points of series B were analyzed, which may result in less accuracy of the derived critical dose than that from series A. The radiation dose versus normalized OD data points were fit to eq 2 using extrapolated normalized $\mathrm{OD}_{\infty}$ values of $0.40(5)$ at $288.2 \mathrm{eV}, 1.00(5)$ at $286.5 \mathrm{eV}$, and $0.40(5)$ at $284.8 \mathrm{eV}$. The final derived critical doses for the two series of electron beam damage are listed in Table 2. The values of series B seem systematically lower than those of series A, probably due to insufficient sampling of the dose-damage curve in series B. Nevertheless, the critical doses determined for damage by an $80 \mathrm{keV}$ electron beam, especially from series A, are in good agreement with the critical dose for $300 \mathrm{eV}$ X-ray damage.
The critical doses derived at 288.2 and $286.5 \mathrm{eV}$ are quite similar, as expected since they characterize the same damage pathway. The critical dose determined at $284.8 \mathrm{eV}$ is slightly but consistently lower than the critical doses determined at 288.2 and $286.5 \mathrm{eV}$. At first glance this seems unexpected since other studies $^{7,11}$ consistently show that critical doses for destruction of $\mathrm{C}=\mathrm{C}$ bonds in phenyl rings are much larger than critical doses for damage to $\mathrm{C}=\mathrm{O}$ or $\mathrm{C}-\mathrm{O}$ bonds. We note that there is only a redistribution of the $\pi^{*}{ }_{\mathrm{C}=\mathrm{C}}$ intensity, not a net loss (see Figure 1a inset). Thus, the relatively fast change of intensity at $284.8 \mathrm{eV}$ reflects disruption of the delocalization of the carbonyl and phenyl ring, which would occur even if there are only changes in the relative orientation of the phenyl ring and the ester group, and certainly would occur whenever the phenyl-ester bond is broken. In the previous study ${ }^{5}$ the electron beam damage was performed at a much higher dose rate and continued to a higher final dose. At these higher doses damage to the phenyl ring starts to occur, and was included in the evaluation. Compared to the previous measurements, ${ }^{5}$ the critical doses derived in this work for damage from X-ray and electrons are in much better agreement. The mean critical dose of X-ray damage to PET and electron beam damage series A is 4.3(6) $\times$ $10^{2} \mathrm{MGy}$ and $4.0(6) \times 10^{2} \mathrm{MGy}$ respectively. These values are the same when estimated uncertainties are considered. Thus, our best estimate of the mean critical dose for damage to the ester group of PET by X-ray and electron beam is $4.2(6) \times 10^{2}$ MGy. The degradation of the ester group is accompanied by creation of isolated $\mathrm{C}=\mathrm{O}$ aldehyde or ketone groups at the same rate.

3.3. PET Damage in the $O$ 1s Edge. A thicker PET film $(250(8) \mathrm{nm}$ ) was damaged by $531.6 \mathrm{eV}$ photons, the energy of the $\mathrm{O} 1 \mathrm{~s} \rightarrow \pi_{\mathrm{C}=\mathrm{O}}^{*}$ transition. Figure 4 presents the quantitative determination of critical dose for this damage to PET, as monitored at 531.6 and $534.1 \mathrm{eV}$. Figure 4a shows relative optical density images at 526, 531.6, 534.1, and $560 \mathrm{eV}$ of a uniform region of a PET film that was damaged by the ninepad pattern with indicated dwell time per pixel between 62.5 and $2500 \mathrm{~ms}$. The damage of the ester group was monitored at 531.6 and $534.1 \mathrm{eV}$, and the carbon mass loss was evaluated at $526 \mathrm{eV}$ whereas oxygen mass loss was evaluated at $560 \mathrm{eV}$. The damage pattern was clearly visualized at each of these four 

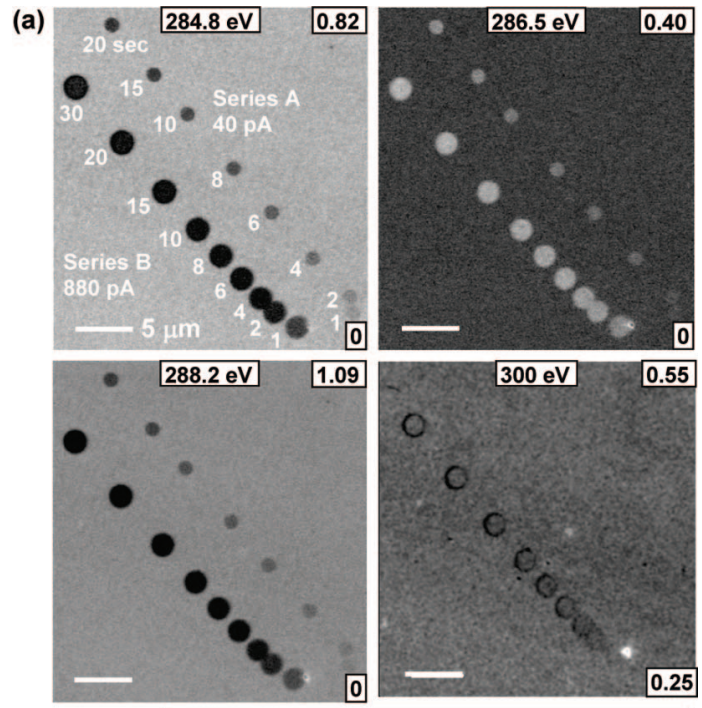

(b)

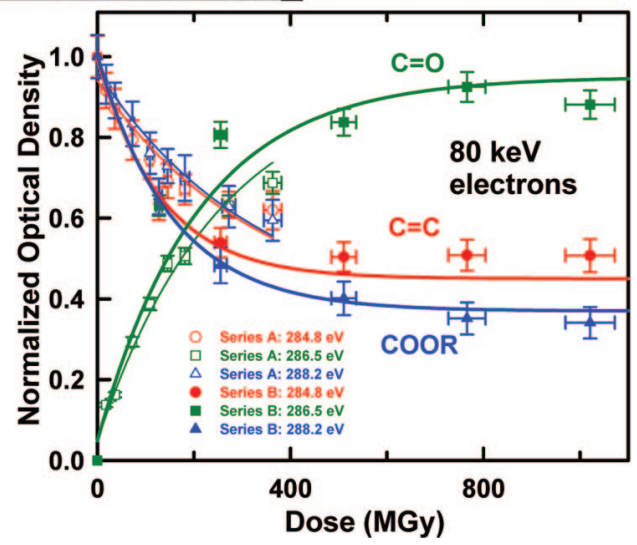

Figure 3. C 1s STXM analysis of $80 \mathrm{keV}$ electron beam damage of PET. (a) Two series of spots were created in an initially undamaged, free-standing uniform PET thin film by exposure with a TEM electron beam of $80 \mathrm{keV}$ energy. Series A spots were made by 1-20 s exposures of PET to a $1.3 \mu \mathrm{m}$ diameter, $40 \mathrm{pA}$ electron beam. The series B spots were made with $1-30 \mathrm{~s}$ exposures of PET to a $2.6 \mu \mathrm{m}$ diameter 880 pA electron beam The sample was then imaged by STXM at 284.8 , $286.5,288.2$, and $300 \mathrm{eV}$. The numbers in the lower and upper right boxes are the optical density scale for each image. The rim around the higher exposure spots visible in the image at $300 \mathrm{eV}$ arises from knockon damage. ${ }^{26,27}$ (b) Plots of the normalized optical density at 284.8 , 286.5, and $288.2 \mathrm{eV}$ as a function of radiation dose for PET damaged by exposure to $80 \mathrm{keV}$ electrons.

energies, indicating that both chemical changes and significant oxygen mass loss occur with bombardment at $531.6 \mathrm{eV}$. Because absorption in the exposed sample area significantly decreases with exposure time, the changes in the OD were evaluated by integration of the changes in OD over the exposure time ${ }^{11}$ and used in evaluating the actual dose. For the $\mathrm{O} 1 \mathrm{~s}$ damage in this work, the instantaneous dose rate decayed exponentially from $6.1(3) \times 10^{2}$ to $4.8(2) \times 10^{2} \mathrm{MGy} / \mathrm{s}$ between 62.5 and 2500 $\mathrm{ms}$. The data points of radiation dose versus normalized OD were fit to eq 2 with extrapolated normalized $\mathrm{OD}_{\infty}$ of $0.30(5)$ at $531.6 \mathrm{eV}$ and $0.20(5)$ at $534.1 \mathrm{eV}$. The derived critical doses are summarized in Table 3 and are 6.3(9) $\times 10^{2}$ MGy when measured at $531.6 \mathrm{eV}$ and 4.5(7) $\times 10^{2}$ MGy when measured at $534.1 \mathrm{eV}$. The critical dose for changes to the $\pi_{\mathrm{C}=\mathrm{O}}^{*}$ signal is higher than that for degradation of the $\mathrm{C}-\mathrm{O}$ bond. This difference is likely due to the fact that the signal at $531.6 \mathrm{eV}$ incorporates more complicated chemical changes since it reflects damage to both the ester group of PET and the carbonyl group of the benzaldehyde moieties produced in the ester degradation.

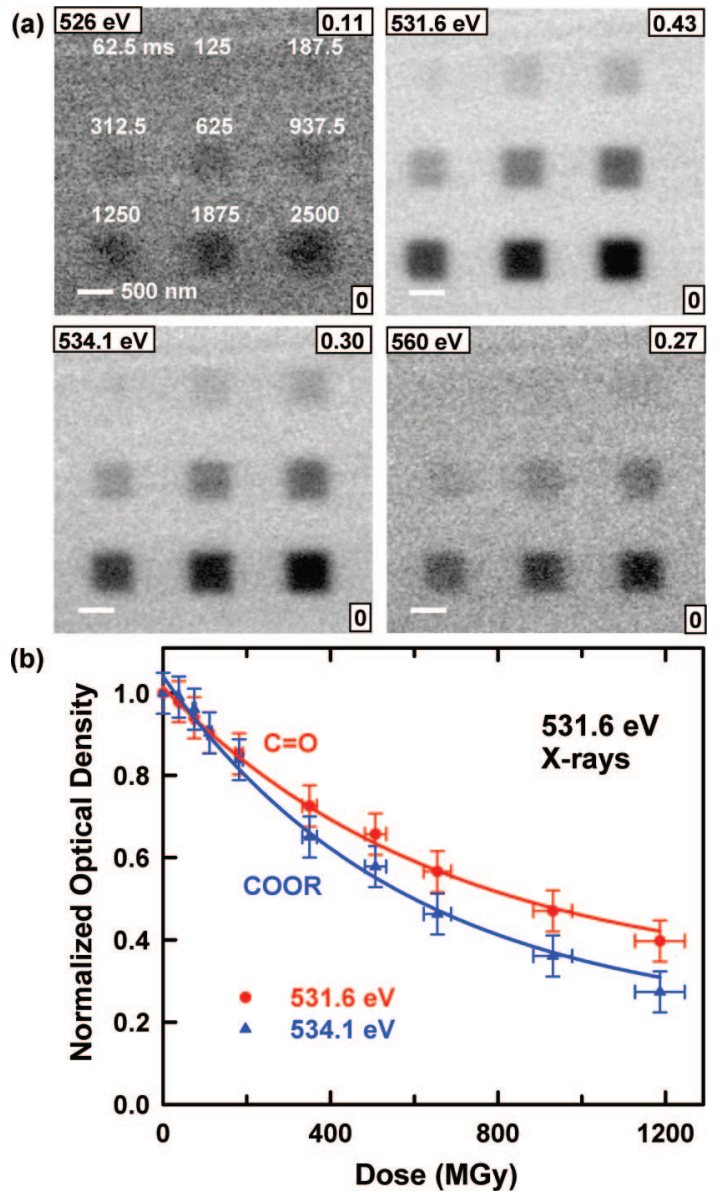

Figure 4. STXM damage of PET at the O 1s edge. (a) Patterns created in an initially undamaged, free-standing uniform $250(8) \mathrm{nm}$ thin film by exposure at $531.6 \mathrm{eV}$ using a $10 \times 10$ pixel, $0.6 \mu \mathrm{m} \times 0.6 \mu \mathrm{m}$ raster scan with the indicated per-pixel dwell times. Due to the rapid oxygen mass loss the dose rate decayed exponentially from $6.1(3) \times$ $10^{2}$ to $4.8(2) \times 10^{2} \mathrm{MGy} / \mathrm{s}$. The damaged region was then imaged at 526, 531.6, 534.1, and $560 \mathrm{eV}$. (b) Plots of the normalized optical density at 531.6 and $534.1 \mathrm{eV}$ as a function of radiation dose for PET damaged by exposure to $531.6 \mathrm{eV}$ X-rays.

Similar complexity was also found in the C 1s edge when determining the critical dose at $284.8 \mathrm{eV}$, an energy that reflects both cleavage between the ester group and the phenyl ring, and nominal damage of the phenyl ring. When a pure chemical process was chosen to determine the critical dose, for example, the $\mathrm{C}-\mathrm{O}$ bond dissociation in the ester group, as monitored at $288.2 \mathrm{eV}$ in the $\mathrm{C} 1 \mathrm{~s}$ edge and at $534.1 \mathrm{eV}$ in the $\mathrm{O} 1 \mathrm{~s}$, consistent results were obtained regardless of the absorption edge, the experimental conditions (dose rate, sample thickness, etc.), and the radiation used.

X-ray damage was also studied by irradiation at 528, 534.1, and $540.5 \mathrm{eV}$ in the $\mathrm{O} 1 \mathrm{~s}$ region. Figure 5 plots a series of $\mathrm{O}$ 1s spectra for damage at 531.6 and $534.1 \mathrm{eV}$. Table 3 lists the derived critical doses. The difference in the critical dose derived from the spectra measured at $531.6 \mathrm{eV}$ (carbonyl) and 534.1 $\mathrm{eV}$ (ester) is particularly striking (700 versus $450 \mathrm{MGy}$ ), and the effect is readily observed by comparing the extent of change at any given dose in the intensities of the peaks at 531.6 and $534.1 \mathrm{eV}$ (Figure 5). However, when comparing evaluations at the same analysis energy, there was no detectible difference in the critical dose for damage by irradiation at 528, 531.6, 534.1, and $540.5 \mathrm{eV}$. This is in considerable contrast to soft X-ray damage studies of ester-containing polymers evaluated by total and partial ion yield measurements where there are very strong 
TABLE 3: Photon Energies, Normalized Infinite Optical Densities, and Derived Critical Doses from O 1s Analysis of PET Damaged in the O 1s Region by Monochromatic X-rays or an $80 \mathrm{keV}$ Electron Beam

\begin{tabular}{|c|c|c|c|c|c|c|c|}
\hline \multirow[b]{2}{*}{ damage process } & \multirow[b]{2}{*}{ parameter } & \multicolumn{4}{|c|}{ STXM damage measured at E $(\mathrm{eV})$} & \multirow[b]{2}{*}{ TEM damage A } & \multirow[b]{2}{*}{ TEM damage $\mathrm{B}$} \\
\hline & & 5280.0 & 531.6 & 534.1 & 540.5 & & \\
\hline $\mathrm{O}=\mathrm{COR}$ damage $531.6 \mathrm{eV}$ & $\mathrm{OD}_{\infty}{ }^{a}$ & $0.30(5)$ & $0.30(5)$ & $0.30(5)$ & $0.30(5)$ & $0.10(5)$ & $0.10(5)$ \\
\hline \multirow[t]{2}{*}{$\mathrm{OC}-\mathrm{OR}$ damage $534.1 \mathrm{eV}$} & $\mathrm{OD}_{\infty}{ }^{a}$ & $0.20(5)$ & $0.20(5)$ & $0.20(5)$ & $0.20(5)$ & $0.20(5)$ & $0.20(5)$ \\
\hline & critical dose $\left(\times 10^{2}\right.$ MGy $)$ & 4.1(3) & $4.5(7)$ & $4.5(7)$ & $4.4(7)$ & $5.0(7)$ & $5.1(7)$ \\
\hline oxygen mass loss $526-560 \mathrm{eV}$ & $\mathrm{OD}_{\infty}{ }^{a}$ & $0.50(5)$ & $0.50(5)$ & $0.50(5)$ & $0.50(5)$ & $0.30(5)$ & $0.30(5)$ \\
\hline
\end{tabular}

${ }^{a} \mathrm{OD}_{\infty}$ is the normalized optical density after infinite dose.

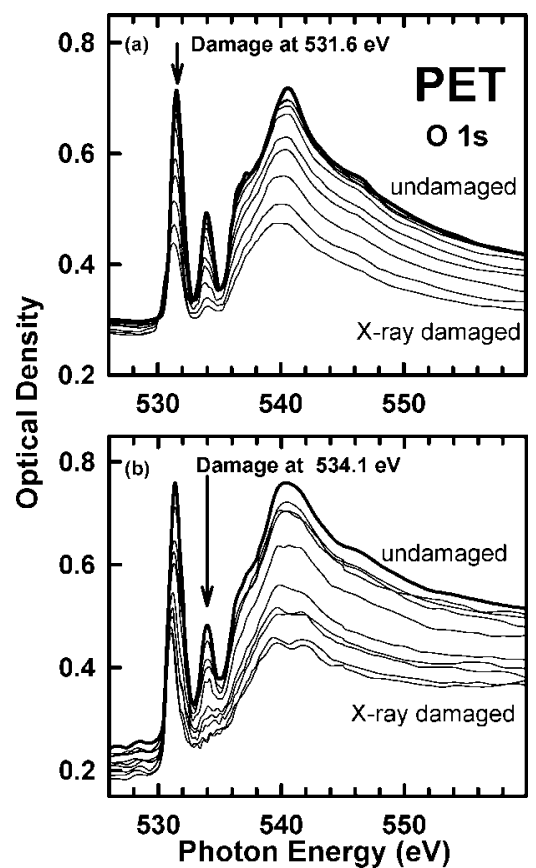

Figure 5. O 1s spectra of PET exposed for a series of exposure times at (a) $531.6 \mathrm{eV}$, where the dose rate decayed exponentially from 6.1(3) $\times 10^{2}$ to $4.8(2) \times 10^{2} \mathrm{MGy} / \mathrm{s}$; and (b) $534.1 \mathrm{eV}$, where the dose rate decayed exponentially from $9.2(4) \times 10^{2}$ to $6.2(3) \times 10^{2} \mathrm{MGy} / \mathrm{s}$.

changes in the critical dose and chemistry..$^{30-32}$ This is because the ion yield measurements reflect the primary damage processes. This observation emphasizes that the net damage measured in this work is dominated by integration over a wide range of secondary processes, which tend to mask differences that might occur in primary damage events. To recap, for any given damage pathway similar critical doses are obtained, independent of the exposure energy used.

The critical doses for the two series of electron beam damage were also evaluated from the spectral changes at 531.6 and 534.1 $\mathrm{eV}$, as listed in Table 3. Compared to X-ray damage, the critical dose at $531.6 \mathrm{eV}$ is more similar to that at $534.1 \mathrm{eV}$ for electron beam damage. This is probably due to a larger oxygen mass loss rate for electron beam damage relative to X-ray damage. The loss of $\mathrm{O}$ atoms dominates the electron beam damage process and masks the complicated chemistry changes at 531.6 $\mathrm{eV}$.

\section{Discussion}

Radiation damage to polymers and other materials by soft $\mathrm{X}$-rays and high-energy electrons can be divided into two stages, primary processes and secondary processes. ${ }^{8,11}$ The primary processes in TEM include: inelastic scattering causing dipole (and to a much smaller extent, nondipole) valence electron excitation and ionization, collective valence losses (plasmons), plus a very small amount of inner shell excitation and ionization. In STXM, the primary process is resonant absorption that almost exclusively creates specific inner shell excited or ionized states when monochromated photon energies are used. In both cases the initially created excited and ionized states will undergo further evolution, with the greatest additional charged particle creation occurring from Auger decay of the core excited and ionized states. ${ }^{33,34}$ In both situations, although the primary processes are quite different, there are quite similar secondary processes that involve generation of lower energy secondary electrons, free radicals, and ions, followed by transport of these species in the material and generation of more charged particles or reactive species in chain reaction processes. We emphasize again that there are considerable differences in the primary processes $-80 \mathrm{keV}$ electron impact produces mainly collective multiple valence excitations (plasmons) and single valence ionization-whereas the 300-550 eV X-rays produce almost exclusively inner-shell ionization. In general, the ejected electrons and ions produced in the initial (primary) interaction will be less energetic in TEM than in STXM. Despite that, the very similar damage chemistry and critical doses for electron and X-ray damage indicate that secondary processes dominate net radiation damage.

\section{Conclusions}

The chemical changes and absolute rates for radiation damage to polyethylene terephthalate (PET) by soft X-rays and energetic electrons have been measured. The spectral changes were similar for damage by electrons and $\mathrm{X}$-rays, indicating the radiation chemistry is dominated by secondary processes, not the primary event. The critical dose for chemical changes is $4.2(6) \times 10^{8}$ Gy and was the same for soft X-rays and electrons within measurement uncertainties. The critical dose for specific damage processes (as defined by changes in several different, bondspecific spectral features) was found to be similar in the $\mathrm{C} 1 \mathrm{~s}$ region and comparable between $\mathrm{C} 1 \mathrm{~s}$ and $\mathrm{O}$ 1s edges for electron beam damage.

Acknowledgment. This research is supported by NSERC (Canada), the Canada Foundation for Innovation (CFI), and the Canada Research Chair Program. We thank David Kilcoyne and Tolek Tyliszczak for expert maintenance of STXM532, and Daniel Hernandez-Cruz for assistance with STXM operations. Construction and operation of the STXM 5.3.2 microscope is supported by NSF DMR-9975694, DOE DE-FG02-98ER45737, Dow Chemical, NSERC, and CFI. The Advanced Light Source is supported by the Director, Office of Energy Research, Office of Basic Energy Sciences, Materials Sciences Division of the U.S. Department of Energy, under Contract No. DE-AC0376 SF00098.

\section{References and Notes}

(1) Lawes, R. A. Appl. Surf. Sci. 2000, 154-155, 519-526. 
(2) Schnabel, W., Polymer Degradation: Principles and Practical Applications; Macmillan: New York, 1981.

(3) Singh, A. Silverman, J., Radiation Processing of Polymers; Hanser Publishers, Oxford University Press: New York, 1991.

(4) Zhang, X.; Jacobsen, C.; Lindaas, S.; Williams, S. J. Vac. Sci. Technol. B 1995, 13, 1477-1483.

(5) Rightor, E. G.; Hitchcock, A. P.; Ade, H.; Leapman, R. D.; Urquhart, S. G.; Smith, A. P.; Mitchell, G.; Fischer, D.; Shin, H. J.; Warwick, T. J. Phys. Chem. B 1997, 101, 1950-1960.

(6) Coffey, T.; Urquhart, S. G.; Ade, H. J. Electron Spectrosc. Relat. Phenom. 2002, 122, 65-78.

(7) Beetz, T.; Jacobsen, C. J. Synchrotron Rad. 2002, 10, 280-283.

(8) Wang, J.; Stöver, H. D. H.; Hitchcock, A. P.; Tyliszczak, T. J. Synchrotron Rad. 2007, 14, 181-190.

(9) Wang, J.; Stöver, H. D. H.; Hitchcock, A. P. J. Phys. Chem. C 2007, 111, 16330-16338.

(10) Hitchcock, A. P.; Dynes, J. J.; Johansson, G.; Wang, J.; Botton, G. Micron 2008, 39, 311-319.

(11) Wang, J., Morin, C., Li, L., Hitchcock, A. P. Scholl, A. Doran, A J. Electron Spectrosc. Relat. Phenom. 2008, doi: 10.1016/j.elspec.2008.01.002

(12) Kaznacheyev, K.; Osanna, A.; Jacobsen, C.; Plashkevych, O.; Vahtras, O.; Ågren, H.; Carravetta, V.; Hitchcock, A. P. J. Phys. Chem. B 2002, 106, 3153-3168.

(13) Dhez, O.; Ade, H.; Urquhart, S. G. J. Electron Spectrosc. Relat. Phenom. 2003, 128, 85-96.

(14) Hitchcock, A. P.; Morin, C.; Zhang, X.; Araki, T.; Dynes, J.; Stöver,

H.; Brash, J.; Lawrence, J. R.; Leppard, G. G. J. Electron Spectrosc. Relat.

Phenom. 2005, 144-147, 259-269.

(15) Ade, H.; Hitchcock, A. P. Polymer 2008, 49, 643-675.

(16) Dynes, J. J.; Tyliszczak, T.; Araki, T.; Lawrence, J. R.; Swerhone, G. D. W.; Leppard, G. G.; Hitchcock, A. P. Environ. Sci. Technol. 2006 40, 1556-1565.

(17) Dynes, J. J.; Lawrence, J. R.; Korber, D. R.; Swerhone, G. D. W.; Leppard, G. G.; Hitchcock, A. P. Sci. Total Environ. 2006, 369, 369-383.

(18) Goodfellow R\&D Materials, http://www.goodfellow.com (accessed 1/2009).
(19) Ade, H.; Urquhart, S. G., In: Chemical Applications of Synchrotron Radiation; Sham T. K., Ed.;World Scientific Publishing: Singapore, 2002. (20) Urquhart, S. G.; Ade, H. J. Phys. Chem. B 2002, 106, 8531-8538. (21) Warwick, T.; Ade, H.; Kilcoyne, D.; Kritscher, M.; Tylisczczk, T.; Fakra, S.; Hitchcock, A.; Hitchcock, P.; Padmore, H. J. Synchrotron Rad. 2002, 9, 254-257.

(22) Kilcoyne, A. L. D.; Tyliszczak, T.; Steele, W. F.; Fakra, S.; Hitchcock, P.; Franck, K.; Anderson, E.; Harteneck, B.; Rightor, E. G.; Mitchell, G. E.; Hitchcock, A. P.; Yang, L.; Warwick, T.; Ade, H. J. Synchrotron Rad. 2003, 10, 125-136.

(23) Wang, J., Radiation Chemistry by Soft X-Ray Spectromicroscopy. Ph.D. Thesis, McMaster University, 2008.

(24) Korde, R., Prince, C., Cunningham, D., Vest, R. E., Gullikson, E., Metrologia 40 (2003) S145. Calibrated silicon photodiodes were obtained from International Radiation Detectors, 2527 West 237th Street Unit A, Torrance, CA90505-5243.

(25) Jacobsen, C.; Wirick, S.; Flynn, G.; Zimba, C. J. Microsc. 2000, 197, 173-184.

(26) Dietrich, I.; Fox, F.; Heide, H. G.; Knapek, E.; Weyl, R. Ultramicroscopy 1978) , 3, 185-189.

(27) Massover, W. H. J. Synchrotron Radiation 2007, 14, 116-127.

(28) Akar, A.; Gümüş, H.; Okumuşoǧlu, N. T. Appl. Radiat. Isot. 2006, $64,543-550$

(29) Cooney, R. R.; Urquhart, S. G. J. Phys. Chem. B 2004, 108, 1818518191.

(30) Sekitani, T.; Ikenaga, E.; Fujii, K.; Mase, K.; Ueno, N.; Tanaka, K. J. Electron Spectrosc. Relat. Phenom. 1999, 101-103, 135-140.

(31) Tanaka, K.; Sako, E. O.; Ikenaga, E.; Isari, K.; Sardar, S. A.; Wada, S.; Sekitani, T.; Mase, K.; Ueno, N. J. Electron Spectrosc. Relat. Phenom. 2001, 119, 255-266.

(32) Wada, S.; Sako, E. O.; Sumii, R.; Waki, S.; Isaria, K.; Sekiguchi, T.; Sekitani, T. K. Tanaka Nucl. Inst. Meth. B 2003, 199, 361-365.

(33) Cazaux, J. Microsc. Microanal. Microstruct. 1995, 6, 345-362.

(34) Cazaux, J. J. Microsc. 1997, 188, 106-124.

JP808289E 